\title{
Delusional Belief induced by clomiphene treatment
}

\begin{abstract}
We report the case of a 35 year old women who developed a complex paranoid delusion during the course of clomiphene treatment für ovulation. The psychopathology was remarkable, because after a short hypomanic period the patient was without severe cognitive disturbance but struggled with a complex monothematic delusion. The delusion vanished in the course of a combination treatment with olanzapine a cognitive behavioral therapy. We could not entirely rule out the possibility of an endogenous psychiatric disease but nevertheless we encountered an unusual monothematic delusion which showed a strong temporal correlation with the intake of clomiphene. We provide some speculation about underlying neurobiological mechanisms on the basis of the dopamine theory of delusion.
\end{abstract}

\section{INTRODUCTION}

Clompihene is a selective oestrogen receptor modulator which belongs to the same class of drugs as tamoxiphene. It is used as an ovulation inducer for treating infertility. From a psychiatric point of view we are interested in the psychopathological side effects. In normal healthy women clompihene and other SERMs induce mood lability in up to $50 \%$ of the cases. However more severe alterations of mood and cognition are quite rare. A pubmed search revealed seven cases of psychosis and severe cognition abnormalities in the context of clomiphene treatment (Cashman 1982), Oyffe1997) . In less than $1 \%$ of women treated with clomiphene there are such alterations. Here we present the case of a patient who developed a severe monothematic paranoid delusion, a relatively rare psychopathological syndrome, secondary to her treatment with clomiphene.

\section{CASE REPORT}

Ms. B. was a 35-year-old woman who came to our psychiatric hospital after a week during which she developed a paranoid delusion. She had a history of depression which was treated 10 years ago with a SSRI and psychotherapy. Since then her mood was stabile. Ms. B. was working as a executive in a large German software company. She received a doctorate in mathematics and was working in the software quality management. After a holiday with her husband she started to take $25 \mathrm{mg}$ clomiphene per day because she wanted to get pregnant. In this week there was a change in 
her normal working environment, her chief propagated her to a more responsible position. In this position she has to do lots of organisational work and has many social contacts ranging from up to 150 emails per day to several meetings. One day after her first dose, she noticed a change in her working environment which was described by her as a "vanishing of background noise", which means that she had the impression colleagues talked only to her, no other conversations between colleagues took place. Form the third day on she started to experience ideas of reference, her chief was making hidden suggestions and she had the idea that there was going something on. At the end of the week she was quite disturbed and after having worked for 14 hours she suddenly had the idea that the whole working environment was nothing than a test of her capabilities. She called this the assessment-centre-situation, which meant that her whole behaviour was evaluated by a hidden evaluation team. But more and more she suffered from paranoid ideas, which meant, that her husband, a 42-year-old free-working theologian, was at the centre of a complex conspiracy. The plot of this conspiracy was to test the ability of the software company to react in a "worst-case scenario" in the appropriate way. Her fear was that the software company will cease to exist when she was not able to deliver this message

On the day of the admission, ms. B. was in a very agitated mood and was brought by her husband in our hospital. We started treatment with $10 \mathrm{mg}$ olanzapine. EEG, brain MR and laboratory testing revealed no abnormalities. A neurological examination was negative.

A mental status examination showed no cognitive impairment, only a psychomotoric agitation and slight ideas of reference. At the centre of her psychopathological abnormalities was the "worstcase” delusion, which meant, that she had to inform some unknown superior executive in her company or the government.

She tried to convince us that she had to speak with a higher official from our hospital. After two Days her BPRS dropped from 42 to 28, delusions counting for most of the points. She was able to reflect upon her delusions in a very logical way. She rejected the suggestion that e. g. a foreign secret agency was behind the conspiracy as "unusual” and "Hollywood-like”. This underlines that the disorder was not only a broad disturbance manifesting as diffuse paranoia on the base of ideas of reference but was highly systematised, a condition which is seen in common only after several years of delusional disorder. She was able to admit that her whole story sounded very unlikely. She talked about the problem of trusting people. She always feared that people were in fact bought by the conspiracy leader as a tool for the worst-case-scenario simulation. Additionally to the antipsychotic therapy, we probed here delusions via a kind of cognitive therapy. Since she had the impression, that the whole scenario converged on a critical day, she began feeling quite hopeless one day before that. To her surprise nothing bad happened on this day and the rest of her delusion 
vanished within three days in several steps. At first, she left the belief of the "worst-case scenario" instead she favoured the explanation of an assessment-centre situation. At the end of her treatment she was convinced that the whole episode was an accident due to the clomiphene treatment. She was released and continued a ambulant psychiatric treatment with olanzapine for six months. She continued working in her former company.

\section{DISCUSSION}

Via pubmed-search (“clomiphene” and "psychosis” as search terms) we discovered seven cases of psychotic syndromes due to clomiphene, none of them presenting as a circumscribed delusional disorder. Siedentopf et. al describe the case of a 32 year old with severe formal thought disorder three days after the beginning of clomiphene treatment Siedentopf et al. (1997) . Kapfhammer et al. describe the case of a 25 year old with a former history of manic-depressive disease and disturbance of consciousness, psychomotoric abnormalities and a paranoid-hallucinatory syndrome with transient neurological dysfunction. In both cases there was a clear psychiatric history highlighting a vulnerability trait.

It is interesting to speculate about the pathophysiological aetiology of this clomiphene induced disorder. Cognitive Neuropsychiatry stated that persecutory delusions could emerge as misinterpretations of social interactions rather than of neutral events . Our patient was acting in a highly social environment. Spitzer provided a model for delusions on the basis of a neural network where he simulated different dopamine levels via the gain-parameter Spitzer (1995) . A higher dopamine level led to an improved forming of representational nodes within this network which could be interpreted as the basis for ideas of reference; recognising a "gestalt" where none has been before. How could clomiphene possibly modulate dopamine neurotransmission? On the basis of animal experiments it has been shown that progesterone and oestrogen have strong priming effects for dopamine in the limbic system Arvin et al. (2000) Becker (2000). Rats treated with the selective estrogen receptor modulator tamoxifene show a much higher dopamine signal in the nigrostriatal system McDermott et al. (1997) . This may be the underlying cause of the delusional formation in our patient, pointing to a exciting interaction of endocrinological influences on higher cognitive functions.

From a clinical point of view this case proofs the importance of a thorough psychiatric history taking. Patients with a psychiatric history may be especially vulnerable to the psychic side effects of clomiphene. From a neurobiological point of view the case provides interesting insights in the interactions of hormones and behaviour. It is fascinating to see how a small hormonal dysbalance leads to a severe cognitive disorder. The research done in animals has to be expanded to humans, so 
we possibly could understand the effects post-partum psychosis or drug side effects from hormones. Clomiphene may be an interesting tool for the evaluation of cognitive effects of sex hormones on the brain.

\section{REFERENCES}

Arvin, M., Fedorkova, L., Disshon, K. A., Dluzen, D. E. and Leipheimer, R. E. "Estrogen modulates responses of striatal dopamine neurons to $\operatorname{MPP}(+)$ : evaluations using in vitro and in vivo techniques." Brain Res, 2000, 872(1-2), pp. 160-71.

Becker, J. B. "Oestrogen effects on dopaminergic function in striatum." Novartis Found Symp, 2000, 230pp. 134-45; discussion 145-54.

Cashman, F. E. and Sheppard, R. "Clomiphene citrate as a possible cause of psychosis." Can Med Assoc J, 1982, 126(2), pp. 118.

McDermott, J. L., Anderson, L. I. and Dluzen, D. E. "Interactive effects of tamoxifen and estrogen upon the nigrostriatal dopaminergic system." Neuroendocrinology, 1997, 66(3), pp. 181-7.

Oyffe, I., Lerner, A., Isaacs, G., Harel, Y. and Sigal, M. "Clomiphene-induced psychosis." Am J Psychiatry, 1997, 154(8), pp. 1169-70.

Siedentopf, F., Horstkamp, B., Stief, G. and Kentenich, H. "Clomiphene citrate as a possible cause of a psychotic reaction during infertility treatment." Hum Reprod, 1997, 12(4), pp. 706-7.

Spitzer, M. "A neurocomputational approach to delusions." Compr Psychiatry, 1995, 36(2), pp. 83-105. 